\title{
Serum testosterone depression as a factor influencing the general condition in chronic obstructive pulmonary disease patients
}

\author{
Renata Rubinsztajn ${ }^{A-D, F}$, Tadeusz Przybyłowski, ${ }^{B, C, E, F}$, Marta Maskey-Warzęchowska ${ }^{B, E, F}$, Krzysztof Karwat ${ }^{B, F}$, Ryszarda Chazan ${ }^{A, E, F}$ \\ Department of Internal Medicine, Pulmonary Diseases and Allergy, Medical University of Warsaw, Poland \\ A - research concept and design; B - collection and/or assembly of data; C - data analysis and interpretation; \\ $D$ - writing the article; $E$ - critical revision of the article; $F$ - final approval of the article
}

Address for correspondence

Renata Rubinsztajn

E-mail: rrubinsztajn@wum.edu.pl

\section{Funding sources}

National Centre for Research and Development; project "Chronic obstructive pulmonary disease (COPD) - systemic disease, the biggest threat of the $21^{\text {st }}$ century" (No. 13 0034 06/2009).

Conflict of interest None declared

\section{Acknowledgements}

We would like to thank Barbara Mackiewicz MD, PhD for her help in data collection.

Received on July 27, 2017

Reviewed on January 24, 2018

Accepted on August 9, 2018

Published online on March 6, 2019

\begin{abstract}
Background. Testosterone has been recognized for its anabolic properties. It has been documented that in patients with chronic obstructive pulmonary disease (COPD), chronic hypoxia, disease severity, smoking, and corticosteroid treatment may contribute to low testosterone levels.
\end{abstract}

Objectives. The aim of the study was to evaluate the incidence of decreased serum testosterone concentration in male COPD patients and its influence on their condition.

Material and methods. The study group consisted of 90 male patients, aged $67.2 \pm 8.8$ years in all stages of airflow limitation severity (mild $n=6$, moderate $n=43$, severe $n=28$ and very severe $n=13$ ) Serum testosterone concentration was evaluated using ELISA method (Testosterone ELISE LDN). Decreased serum testosterone level was defined as a value of less than $3 \mathrm{ng} / \mathrm{mL}$. Testosterone levels were related clinical features of COPD.

Results. Serum testosterone concentration did not differ in patients with different stages of airflow limitation severity $(3.8 \pm 0.7 \mathrm{ng} / \mathrm{mL}$ for mild: $3.6 \pm 2.1 \mathrm{ng} / \mathrm{mL}$ for moderate; $3.4 \pm 1.2 \mathrm{ng} / \mathrm{mL}$ for severe and $3.7 \pm 1.7 \mathrm{ng} / \mathrm{mL}$ for very severe, respectively). Decreased serum testosterone was found in 30 patients (group A). There were no differences in age, the number of exacerbations or CRP concentration between patients with decreased and the normal serum testosterone group (group B). Group A was characterized by a lower FEV1, shorter 6-minute walking distance, longer smoking history and higher BMI, but no differences in body composition and densitometry results were found.

Conclusions. Serum testosterone depression may occur in as much as 30\% of male COPD patients in all COPD stages of severity. The relationship between serum testosterone and negative COPD prognostic factors indicates its influence on the natural history of the disease.

Key words: quality of life, body composition, COPD, testosterone
Cite as

Rubinsztajn R, Przybyłowski T, Maskey-Warzęchowska M, Karwat K, Chazan R. Serum testosterone depression as a factor influencing the general condition in chronic obstructive pulmonary disease patients. Adv Clin Exp Med. 2019;28(6):783-788. doi:10.17219/acem/94153

DOI

10.17219/acem/94153

Copyright

Copyright by Author(s)

This is an article distributed under the terms of the

Creative Commons Attribution Non-Commercial License

(http://creativecommons.org/licenses/by-nc-nd/4.0/) 


\section{Introduction}

Male hypogonadism is a clinical syndrome caused by androgen deficiency which may adversely affect the function of multiple organs and the patient's quality of life. It is due to the disruption of 1 or several levels of the hypothalamic-pituitary-gonadal axis. ${ }^{1}$ Male ageing is characterized by a progressive decline in circulating testosterone by approx. 1-2\% per year. ${ }^{2,3}$ In the European Male Ageing Study, testosterone concentration was lower than $8 \mathrm{nmol} / \mathrm{L}$ in $4.1 \%$ of patients and lower than $11 \mathrm{nmol} / \mathrm{L}$ in $17 \%{ }^{4}$ The results show that the symptoms of poor morning erection, low sexual desire, erectile dysfunction, inability to perform vigorous activity, depression, and fatigue were significantly related to testosterone level. ${ }^{4}$ According to the US Hypogonadism in Males Study, 38.7\% of men aged 45 and above have testosterone deficiency (with the cut-off value set at $300 \mathrm{ng} / \mathrm{dL}) .{ }^{5}$ According to the PolSenior study, $19.9 \%$ of male subjects over 65 years had testosterone concentrations below normal values, in $78.2 \%$ it was within the normal range and in $1.8 \%$ it was over the normal value. ${ }^{6}$ Hypogonadism is associated with such symptoms as body composition changes, gynecomastia, muscular atrophy, osteoporotic fracture, loss of height, sleep disturbance, fatigue, decreased energy, muscle aches, and poor memory. ${ }^{1}$ Some studies have shown that hypogonadism occurs more frequently in some medical conditions, including type 2 diabetes, obesity, dyslipidemia, obstructive sleep apnea, chronic obstructive pulmonary disease (COPD), rheumatoid arthritis, osteoporosis, chronic corticosteroid use, and others. ${ }^{1}$ Important factors that predicted and correlated with hypogonadism were advanced age, obesity, a diagnosis of metabolic syndrome, and a poor general health status. ${ }^{7}$ Decreased plasma testosterone may suggest the presence of cardiovascular risk factors and potentially increased risk for heart disease. ${ }^{8}$ Low testosterone levels may be linked to increased all-cause mortality. The risk for all-cause mortality during an average of 4-16 years' follow-up period was $24-124 \%$ higher in men with low testosterone. ${ }^{7}$ The prevalence of hypogonadism in male COPD patients ranges from 22 to $69 \%,{ }^{9}$ but some studies have shown an insignificant difference in testosterone concentration between COPD and healthy men. ${ }^{2,10,11}$ The mechanism of hypogonadism in COPD patients is unclear. Age, chronic hypoxia and hypercapnia, smoking status, comorbidities and corticosteroid therapy are likely reasons for this condition. ${ }^{9,12}$

The aim of the study was to evaluate the incidence of decreased serum testosterone concentration in male COPD patients and its influence on the general condition.

\section{Material and methods}

The study group consisted of 90 male patients with COPD diagnosis, in all stages of airflow limitation. Chronic obstructive pulmonary disease was diagnosed according to the Global Initiative for Chronic Obstructive Lung Disease (GOLD) definition. ${ }^{13}$ The patients were consecutively enrolled from patients treated on an out-patient basis at the Department of Internal Medicine, Pulmonary Diseases and Allergy at the Medical University of Warsaw. The inclusion criteria were: male sex, age over 50 years, COPD diagnosis, and signed informed consent. The exclusion criteria were: COPD exacerbation in the 4 weeks prior to the study, prostate cancer, treated with testosterone in the 4 weeks prior to the study. The characteristics of study group are presented in Table 1. Medical history and physical examination, including body weight and height, were conducted. The BMI $\left(\mathrm{kg} / \mathrm{m}^{2}\right)$ was calculated. An analysis of body composition was performed using bioimpedance (Tanita T5896, TANITA Corporation of America, Inc., Arlington Heights, USA). Fat mass (FM), fat free mass (FFM), muscle mass (MM), and total body water (TBW) were expressed as indexes $-\mathrm{kg} / \mathrm{m}^{2}$ (FMI, FFMI, MMI, TBWI). Bone mineral density (BMD) within the postero-anterior lumbar spine (level L1-L4) and the femoral neck were assessed by dual-energy X-ray absorptiometry (DEXA) with the use of a Discovery Densitometer (Hologic, Waltham, USA) according to the manufacturer's recommended standard procedures. Spirometry with bronchial reversibility testing after the administration of salbutamol $(400 \mu \mathrm{g})$ via a spacer was performed in accordance with the ATS/ERS recommendations (Lungtest 1000, MES, Skawina, Poland). ${ }^{14}$ Six-minute walk test $(6 \mathrm{MWT})$ was performed in accordance with

Table 1. Characteristics of the study group (median and IQR)

\begin{tabular}{|l|c|}
\hline Age & $66.5(60-75)$ \\
\hline Pack-years & $40.0(26-50)$ \\
\hline Ex-smokers, $n$ [\%] & $63(70.0)$ \\
Active smokers & $23(25.6)$ \\
Never smokers & $4(4.4)$ \\
\hline BMI [kg/m²] & $28.3(24.6-32.0)$ \\
\hline Number of exacerbations/year & $1.0(0-2.0)$ \\
\hline mMRC & $2.0(1.0-2.0)$ \\
\hline BODE index & $2.0(0.0-3.0)$ \\
\hline Post-bronchodilator & $1.53(1.2-1.9)$ \\
\hline FEV 1 /\%predicted & $53.2(44.3-63.1)$ \\
\hline Post-bronchodilator & $3.2(2.7-3.8)$ \\
FVC L/\%predicted & $81.7(67.4-94.5)$ \\
\hline SpO ${ }_{2}$ (\%) at rest & $95.0(93.0-96.0)$ \\
\hline 6MWD [m] & $445.0(370.0-508.0)$ \\
\hline Airflow limitation, $n$ [\%] & \\
mild & $6(10)$ \\
moderate & $43(45.5)$ \\
severe & $28(35.5)$ \\
very severe & $13(9)$ \\
\hline Chronic inhaled corticosteroid & $46(51.1)$ \\
treatment, $n$ [\%] & \\
\hline
\end{tabular}

BMI - body mass index; BODE index - Body-mass index, airflow Obstruction, Dyspnea, and Exercise; $\mathrm{FEV}_{1}$ - forced expiratory volume in the first second; FVC - forced vital capacity; 6MWD - 6-minute walking test distance. 
ATS recommendations. ${ }^{15}$ Dyspnea was assessed according to $\mathrm{mMRC}$ score. ${ }^{16}$ BODE (Body-mass index, airflow Obstruction, Dyspnea, and Exercise) index was calculated for 53 patients. ${ }^{17}$ Complete blood count and serum levels of C-reactive protein (CRP), lipid profile and testosterone concentration were evaluated. Serum testosterone concentration was measured with the enzyme-linked immunosorbent assay (ELISA) method, using Testosterone ELISA LDN (Labor Diagnostika Nord GmbH \& Co.KG, Nordhorn, Germany). Decreased serum testosterone level for male adults was defined as a value lower than $3 \mathrm{ng} / \mathrm{mL} .^{5}$ Quality of life was evaluated using the St. George's Respiratory Questionnaire (SGRQ). ${ }^{18}$ The variables described above (anthropometric data, lung function, body composition, bone density, exercise performance, basic blood biochemical tests, and quality of life) defined the general condition of COPD patients in our study. The study was funded by the National Center for Research and Development; project "Chronic obstructive pulmonary disease (COPD) - systemic disease, the biggest threat of the $21^{\text {st }}$ century" (13 0034 06/2009). The study received the permission of the Ethics Committee of the Medical University of Warsaw (No. KB/207/2008).

\section{Statistical analysis}

Statistical analysis was performed using STATISTICA for Windows software v. 10 (StatSoft, Inc., Tulsa, USA). The Shapiro-Wilk test was used to confirm normal distribution of the data. Normally distributed variables were represented as a mean \pm standard deviation. Variables outside the normal distribution were represented as a median (interquartile range - IQR). Student's t-test or Mann-Whitney U tests were used depending on the distribution of the variables analyzed for intergroup comparisons. The significance of the correlation coefficient was assessed on the basis of the Spearman's rank correlation coefficient. Linear regression was used to analyze the differences in 6MWT distance (6MWTD) between groups with normal and decreased serum testosterone. Six-minute walking test distance was entered into the statistical model as a dependent variable, and BMI, $\mathrm{FEV}_{1}$ and $\mathrm{FVC}$ were used as independent factors. Statistical significance was set to a value of $\mathrm{p}<0.05$ for all tests.

\section{Results}

The median testosterone concentration was 3.53 (2.7-4.3 ng/mL) in all patients. Serum testosterone concentration did not differ in patients at different stages of airflow limitation $(4.1(3.5-4.6 \mathrm{ng} / \mathrm{mL})$ for mild, 3.4 $(2.8-4.3 \mathrm{ng} / \mathrm{mL})$ for moderate, $4.0(2.6-4.2 \mathrm{ng} / \mathrm{mL})$ for severe, and 2.8 (1.6-3.9 ng/mL) for very severe (Fig. 1). Decreased serum testosterone was found in 30 (33.3\%) patients (hypogonadal, group A). There were no differences

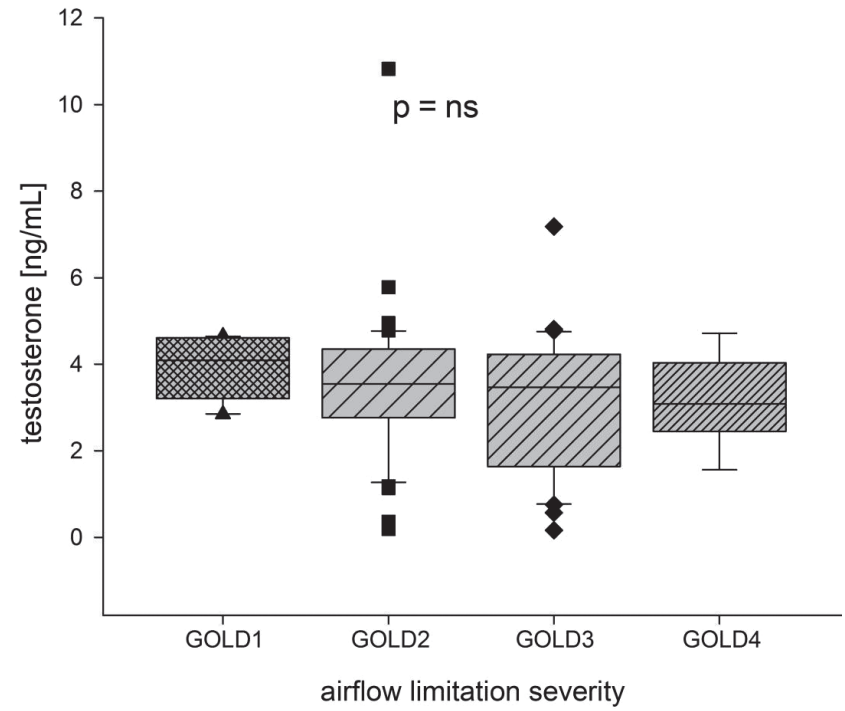

Fig. 1. Serum testosterone in patients at different stages of airflow limitation

The horizontal line within the box indicates the median. The boundaries of the box indicate the $25^{\text {th }}$ and $75^{\text {th }}$ percentiles. The error bars mark the $90^{\text {th }}$ and $10^{\text {th }}$ percentiles. Dotted points represent the outlying values. GOLD1 - FEV ${ }_{1} \%$ FVC $<0.7$ and $\mathrm{FEV}_{1} \geq 80 \%$ of predicted; GOLD2 $-\mathrm{FEV}_{1} \% \mathrm{FVC}<0.7$ and $50 \leq \mathrm{FEV}_{1}<80 \%$ of predicted; GOLD3 - FEV $\%$ FVC $<0.7$ and $30 \leq \mathrm{FEV}_{1}<50 \%$ of predicted; GOLD4 - FEV ${ }_{1} \% \mathrm{FVC}<0.7$ and $\mathrm{FEV}_{1}<30 \%$ of predicted.

in age, the number of exacerbations, CRP or lipid concentrations, or inhaled corticosteroid treatment between patients with decreased and normal serum testosterone. Group A had a higher BMI, a more relevant smoking history and a worse functional performance (Table 2). Sixteen patients (53.3\%) in group A were treated with inhaled corticosteroids $(\mathrm{p}=\mathrm{ns})$ and $6(20.0 \%)$ were active smokers ( $\mathrm{p}=\mathrm{ns}$ ). Despite differences in BMI between the eugonadal and hypogonadal groups, we found no differences in body composition (FMI, FFMI, MMI, or TBWI). The results

Table 2. Differences in variables studied between hypogonadal (A) and eugonadal groups (B), presented as median and IQR

\begin{tabular}{|l|c|c|c|}
\multicolumn{1}{|c|}{ Variables } & Group A & Group B & p-value \\
\hline BMI [kg/m²] & $30.9(24.6-34.3)$ & $26.9(24.0-31.0)$ & 0.01 \\
\hline Pack-years & $40.0(35.0-67.0)$ & $37.0(20.0-50.0)$ & 0.02 \\
\hline $\begin{array}{l}\text { Post-bronchodilator } \\
\text { FVC [L] }\end{array}$ & $2.9(2.4-3.5)$ & $3.4(2.8-4.1)$ & 0.03 \\
\hline $\begin{array}{l}\text { Post-bronchodilator } \\
\text { FEV } 1 \text { [L] }\end{array}$ & $1.3(1.0-1.6)$ & $1.6(1.2-2.1)$ & 0.005 \\
\hline $\begin{array}{l}\text { Post-bronchodilator } \\
\text { FEV } 1 \text { (\%pred.) }\end{array}$ & $47.5(39.0-58.0)$ & $57.5(45.5-65.5)$ & 0.03 \\
\hline SpO (\%) at rest & $94.0(89.0-95.0)$ & $95.0(93.0-96.0)$ & 0.04 \\
\hline $\begin{array}{l}\text { 6MWD [m] } \\
\text { Hemoglobin [g/dL] }\end{array}$ & $14.3(12.6-14.9)$ & $14.8(14.0-15.7)$ & 0.01 \\
\hline
\end{tabular}

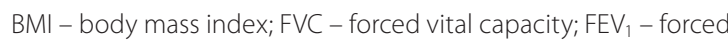
expiratory volume in the first second; $\mathrm{SpO}_{2}(\%)$ - arterial oxygen saturation; 6MWD - 6-minute walking test distance. 
Table 3. Results of the St. George's Respiratory Questionnaire in the groups studied, presented as median and IQR

\begin{tabular}{|l|c|c|c|}
\hline Domains of SGRQ & Group A & Group B & p-value \\
\hline Symptoms & $48.2(26.9-60.6)$ & $48.9(35.0-62.7)$ & 0.7 \\
\hline Activity & $66.3(57.2-85.8)$ & $66.2(47.7-75.0)$ & 0.6 \\
\hline Impact & $41.1(24.8-58.1)$ & $34.5(26.2-46.1)$ & 0.1 \\
\hline Total & $51.8(38.9-63.1)$ & $46.5(36.6-53.8)$ & 0.8 \\
\hline
\end{tabular}

Table 4. Correlations between testosterone concentration and studied variables

\begin{tabular}{|c|c|c|c|}
\hline \multicolumn{2}{|c|}{ Variables } & r & $\mathrm{p}$-value \\
\hline \multirow{7}{*}{$\begin{array}{l}\text { Serum } \\
\text { testosterone } \\
\text { concentration }\end{array}$} & $\mathrm{SpO}_{2}$ at rest (\%) & 0.25 & 0.02 \\
\hline & 6MWD & 0.32 & 0.03 \\
\hline & $\begin{array}{l}\text { post-bronchodilator } \\
\text { FEV }_{1}(\% \text { pred })\end{array}$ & 0.23 & 0.02 \\
\hline & $\begin{array}{l}\text { post-bronchodilator } \\
\qquad \mathrm{FEV}_{1}[\mathrm{~L}]\end{array}$ & 0.28 & 0.005 \\
\hline & $\begin{array}{l}\text { post-bronchodilator } \\
\text { FVC }[\mathrm{L}]\end{array}$ & 0.23 & 0.02 \\
\hline & $\mathrm{BMI}\left[\mathrm{kg} / \mathrm{m}^{2}\right]$ & -0.25 & 0.01 \\
\hline & hemoglobin [g/dL] & 0.24 & 0.03 \\
\hline \multirow{3}{*}{$\begin{array}{l}\text { Lumbar } \\
\text { vertebrae }\end{array}$} & L1-L4 BMD & -0.38 & 0.006 \\
\hline & L1-L4 T score & -0.38 & 0.006 \\
\hline & L1-L4 Z score & -0.33 & 0.01 \\
\hline
\end{tabular}

BMD - bone mass density; FEV 1 - forced expiratory volume in the first second; FVC - forced vital capacity; $\mathrm{SpO}_{2}(\%)$ - oxygen saturation; 6MWD - 6-minute walking distance; L1-L4 - lumbar vertebrae; T-score - bone mineral density at the site when compared to the young normal reference mean; Z score - comparison to age-matched normal.

of densitometry were also comparable between groups, as were the mMRC score and BODE index. We did not observe any relationships between the quality of life assessed using the St. George's Respiratory Questionnaire and testosterone concentration, but the results show a tendency for a decreased quality of life (Table 3). There were 15 hypogonadal patients under 65 years of age. The median testosterone concentration in these patients was $3.38 \mathrm{ng} / \mathrm{mL}$ (IQR 4.0-0.8 ng/mL) vs $3.52 \mathrm{ng} / \mathrm{mL}$ (IQR 2.6-4.4) in patients above 65 years $(\mathrm{p}=\mathrm{ns})$. The following relationships between serum testosterone and the variables investigated were found (Table 4): multivariate analysis showed that inclusion into the analysis was based on independent variables: BMI, FEV 1 (\% of predicted) and FVC (\% of predicted) did not change the statistically significant relationship between 6MWT distance and the decreased or normal serum concentration of testosterone (linear regression, corrected $\mathrm{R}^{2}$ of the model $=0.10 ; \mathrm{p}<0.01$ ).

\section{Discussion}

Our study showed that $1 / 3$ of the investigated cohort of patients with COPD had serum testosterone concentrations below the normal value and this was not dependent on age or inhaled corticosteroid treatment. Although we failed to show differences in serum testosterone concentrations in the 4 degrees of airway obstruction (GOLD1-4), low testosterone patients were characterized by lower $\mathrm{FEV}_{1}, \mathrm{FVC}, \mathrm{SpO}_{2}$ at rest and a shorter 6-minute walking distance. Given the above, it seems that our results confirm the role of testosterone in the general impact of the disease in male patients with COPD.

Smoking is the main COPD risk factor. The influence of smoking on the total testosterone concentration has been the topic of previous studies. Halmenschlager et al. found no relation between smoking and testosterone level ${ }^{19}$ but the results of a meta-analysis showed that in a group of healthy men aged 18-61 years, smokers had a higher mean testosterone than non-smokers. ${ }^{20}$ Moreover, the Tromsø Study showed differences between testosterone concentration in current, ex- and never-smokers. ${ }^{21}$ Our study did not confirm these results.

The next factor associated with COPD is hypoxia. Hypoxia suppresses gonadotropin and testosterone secretion in men with COPD. ${ }^{9}$ A strong correlation between the degree of hypoxia and the degree of testosterone reduction was found by Sempleet al. ${ }^{22}$ Gosney et al. found smaller testis volume and Leydig-cell atrophy in the necropsy of COPD patients. ${ }^{23}$ In our group, oxygen saturation was lower in the hypogonadal group, which is in line with other results. Akbas et al. studied endocrine changes in COPD patients with acute respiratory failure admitted to the intensive care unit. Testosterone concentration tended to be lower in these male patients than in healthy subjects. In 5 (62.5\%) COPD patients, testosterone concentration was below the lower limit. In this group, 3 patients had normal LH and FSH levels (hypogonadotropic hypogonadism) and in 2 patients LH and FSH levels were high (hypergonadotropic hypogonadism) ${ }^{24}$ According to some authors, hypogonadism could be related to acute illnesses and inflammation. ${ }^{24}$ However, other authors disagreed with this hypothesis. ${ }^{11,25,26}$ We found no differences between studied groups with regards to CRP concentration or the number of exacerbations. Chronic obstructive pulmonary disease is characterized by persistent airflow limitation that is usually progressive. ${ }^{13}$ In the Tromsø Study, the reduction in pulmonary function tests was associated with lower levels of free and total testosterone. ${ }^{21}$ Hormones were independently associated with both FVC\%pred. and $\mathrm{FEV}_{1}$ \%pred., and their concentrations were significantly lower in patients with severe and very severe airflow limitation. ${ }^{21}$ In our study, serum testosterone levels did not differ among patients with the 4 degrees of airway obstruction severity (GOLD 1-4), however, we found that patients with lower testosterone levels not only had lower $\mathrm{FEV}_{1}$ and FVC, but were also characterized by lower $\mathrm{SpO}_{2}$ at rest and shorter 6-minute walking distance. This seems to confirm the earlier findings that testosterone levels impact functional performance in male patients with COPD. 
Low testosterone level as an anabolic hormone was associated with muscle wasting. Peripheral muscle wasting is associated with reduced exercise capacity. ${ }^{21}$ Van Vliet et al. found a positive relationship between low androgen status and quadriceps muscle weakness in COPD male patients, but they found no correlations between circulating testosterone concentration and 6MWD. ${ }^{25}$ Lagchi et al. found no differences in 6MWD between hypogonadal and eugonadal patients. ${ }^{27}$ In our hypogonadal group, the 6MWD was shorter, along with resting oxygen saturation. Moreover, lower 6MWD may be related to lower hemoglobin concentration in the low testosterone group. Our results regarding higher BMI in hypogonadal men were the same as in the Laghi study. ${ }^{27}$ Although hypogonadism is associated with the shift in body composition towards more adipose tissue, ${ }^{28}$ we found no differences in FFMI, FMI, MMI, and TBWI.

Hypogonadism is one of the risk factors of osteoporosis. ${ }^{9}$ No differences in bone mass density were found, but L1-L4 $\mathrm{BMD}, \mathrm{T}$-score and Z-score correlated with testosterone concentration. The influence of chronic diseases on the quality of life has been studied by different authors. ${ }^{29,30}$ In our previous study, we reported differences in the individual components of the St George's Respiratory Questionnaire depending on the frequency of exacerbations. ${ }^{31}$ In this study, we found no differences in the SGRQ score between patients with low and normal testosterone concentration. Our results are in line with the Laghi study. ${ }^{27}$ On the other hand, sexual dysfunction is frequent in COPD patients. ${ }^{32,33}$ and it has a negative impact on the quality of life. ${ }^{33}$ According to Collins et al., the prevalence of low testosterone levels was equal in patients with and without sexual dysfunction. ${ }^{33}$ In this study, we did not examine depression as one of the COPD comorbidities, and its correlation with hypogonadism. This was the question of Halabi et al., who found no association between testosterone deficiency and the prevalence of depression. ${ }^{34}$ In medical practice, we should remember that critically ill patients develop significant changes in neuroendocrine axes, including changes in testosterone concentration. ${ }^{35}$ The question is the impact of testosterone supplementation therapy on COPD patients. Atlantis et al. conducted a meta-analysis of 9 observational studies and concluded that testosterone therapy improves exercise capacity. ${ }^{36}$

\section{Study limitations}

This study is limited by the lack of a control group of agematched healthy smokers. In our opinion, we can compare the COPD patients investigated to the subjects studied in the PolSenior Study. As mentioned in the introduction, in the PolSenior Study, 19.9\% of male subjects over 65 years had testosterone concentrations below normal values. ${ }^{6}$ Furthermore, we cannot exclude that the lack of some earlier, strongly-confirmed correlations, such as the correlation between testosterone level and $\mathrm{FEV}_{1}$, may be attributed to the relatively small number of patients studied. However, we would like to emphasize that the earlier observed relationships between testosterone levels and $\mathrm{FEV}_{1}$ have been indirectly confirmed by our findings of lower $\mathrm{FEV}_{1}$ in patients with serum testosterone below the lower limit of normal.

\section{Conclusions}

Serum testosterone depression may occur in as many as $30 \%$ of male COPD patients in all COPD stages of severity. The correlation between serum testosterone and negative COPD prognostic factors may suggest its influence on the natural history of the disease. Larger, multicenter clinical trials are needed to confirm these conclusions and use it in clinical management.

\section{References}

1. Hassan J, Barkin J. Testosterone deficiency syndrome: Benefits, risks, and realities associated with testosterone replacement therapy. Can J Urol. 2016;23(Suppl 1):20-30.

2. Harman SM, Metter EJ, Tobin JD, Pearson J, Blackman MR; Baltimore Longitudinal Study of Aging. Longitudinal effects of aging on serum total and free testosterone levels in healthy men. Baltimore Longitudinal Study of Aging. J Clin Endocrinol Metab. 2001;86(2):724-731.

3. Huhtaniemi I. Late-onset hypogonadism: Current concepts and controversies of pathogenesis, diagnosis and treatment. Asian J Androl. 2014;16(2):192-202.

4. Wu FC, Tajar A, Beynon JM, et al; EMAS Group. Identification of lateonset hypogonadism in middle-aged and elderly men. NEngl J Med. 2010;363(2):123-135.

5. Mulligan T, Frick MF, Zuraw QC, Stemhagen A, McWhirter C. Prevalence of hypogonadism in males aged at least 45 years: The HIM study. Int J Clin Pract. 2006;60(7):762-769.

6. Milewicz A, Krzyżanowska-Świniarska B, Miazgowski T, et al. The reference values of sex hormones and SHBG serum levels in subjects over 65 years old - The PolSenior Study. Endokrynol Pol. 2013;64(2): 82-93.

7. Zarotsky V, Huang MY, Carman W, et al. Systematic literature review of the risk factors, comorbidities, and consequences of hypogonadism in men. Andrology. 2014;2(6):819-834.

8. Chock B, Lin TC, Li CS, Swislocki A. Plasma testosterone is associated with Framingham risk score. Aging Male. 2012;15(3):134-139.

9. Balasubramanian $V$, Naing S. Hypogonadism in chronic obstructive pulmonary disease: Incidence and effects. Curr Opin Pulm Med. 2012; 18(2):112-117.

10. Leifke E, Gorenoi V, Wichers C, Von Zur Mühlen A, Von Büren E, Brabant $\mathrm{G}$. Age-related changes of serum sex hormones, insulin-like growth factor-1 and sex-hormone binding globulin levels in men: Cross-sectional data from a healthy male cohort. Clin Endocrinol (Oxf). 2000;53(6):689-695.

11. Karadag F, Ozcan H, Karul AB, Yilmaz M, Cildag O. Sex hormone alterations and systemic inflammation in chronic obstructive pulmonary disease. Int J Clin Pract. 2009;63(2):275-281.

12. Creutzberg EC, Casaburi R. Endocrinological disturbances in chronic obstructive pulmonary disease. Eur Respir J Suppl. 2003;46:76-80.

13. Global Strategy for the Diagnosis, Management and Prevention of COPD, Global Initiative for Chronic Obstructive Lung Disease (GOLD) 2010. www.goldcopd.org. Accessed March 31, 2017.

14. Miller MR, Hankinson J, Brusasco V, et al; ATS/ERS Task Force. Standardisation of spirometry. Eur Respir J. 2005;26(2):319-338.

15. Brooks D, Solway S, Gibbons WJ. ATS statement on six-minute walk test. Am J Respir Crit Care Med. 2003;167(9):1287.

16. Mahler DA, Wells CK. Evaluation of clinical methods for rating dyspnea. Chest. 1988;93(3):580-586. 
17. Celli BR Cote C, Marin JM, et al. The body-mass index, airflow obstruction, dyspnoea, and exercise capacity index in chronic obstructive pulmonary disease. NEngl J Med.2004;350(10):1005-1012.

18. Jones PW, Quirk FH, Baveystock CM. The St George's Respiratory Questionnaire. Respir Med. 1991;85(Suppl B):25-31.

19. Halmenschlager G, Rossetto S, Lara GM, Rhoden EL. Evaluation of the effects of cigarette smoking on testosterone levels in adult men. J Sex Med. 2009;6(6):1763-1772.

20. Zhao J, Leung JY, Lin SL, Schooling CM. Cigarette smoking and testosterone in men and women: A systematic review and meta-analysis of observational studies. Prev Med. 2016;85:1-10.

21. Svartberg J, Schirmer H, Medbø A, Melbye H, Aasebø U. Reduced pulmonary function is associated with lower levels of endogenous total and free testosterone. Eur J Epidemiol. 2007;22(2):107-112.

22. Semple PD, Beastall GH, Watson WS, Hume R. Serum testosterone depression associated with hypoxia in respiratory failure. Clin Sci (Lond). 1980;58(1):105-106.

23. Gosney JR. Atrophy of Leydig cells in the testes of men with longstanding chronic bronchitis and emphysema. Thorax. 1987;42(8):615-619.

24. Akbaş T, Karakurt S, Unlügüzel G, Celikel T, Akalin S. The endocrinologic changes in critically ill chronic obstructive pulmonary disease patients. COPD. 2010;7(4):240-247.

25. Van Vliet M, Spruit MA, Verleden G, et al. Hypogonadism, quadriceps weakness, and exercise intolerance in chronic obstructive pulmonary disease. Am J Respir Crit Care Med. 2005;172(9):1105-1111.

26. Kaparianos A, Argyropoulou E, Efremidis G, Spiropoulos K. Sex hormone alterations and systemic inflammation in a group of male COPD smokers and their correlation with the +138 insA/delA endothelin-1 gene polymorphism. A case-control study. Eur Rev Med Pharmacol Sci. 2011;15(10):1149-1157.
27. Laghi F, Antonescu-Turcu A, Collins E, et al. Hypogonadism in men with chronic obstructive pulmonary disease: Prevalence and quality of life. Am J Respir Crit Care Med. 2005;171(7):728-733.

28. Arver S, Lehtihet M. Current guidelines for the diagnosis of testosterone deficiency. Front Horm Res. 2009;37:5-20.

29. Wacker ME, Jorres RA, Karch A, et al. Relative impact of COPD and comorbidities on generic health-related quality of life: A pooled analysis of the COSYCONET patient cohort and control subjects from the KORA and SHIP studies. Respir Res. 2016;17:81.

30. Alonso J, Ferrer M, Gandek B, et al; IQOLA Project Group. Healthrelated quality of life associated with chronic conditions in eight countries: Results from the International Quality of Life Assessment (IQOLA) Project. Qual Life Res. 2004;13(2):283-298.

31. Rubinsztajn R, Przybyłowski T, Maskey-Warzechowska, Karwat K, Chazan R. Exacerbations of chronic obstructive pulmonary disease and quality of life of patients. Adv Exp Med Biol. 2016;884:69-74.

32. Köseoğlu N, Köseoğlu H, Ceylan E, Cimrin HA, Ozalevli S, Esen A. Erectile dysfunction prevalence and sexual function status in patients with chronic obstructive pulmonary disease. J Urol. 2005;174(1):249-252.

33. Collins EG, Halabi S, Langston M, Schnell T, Tobin MJ, Laghi F. Sexual dysfunction in men with COPD: Impact on quality of life and survival. Lung. 2012;190(5):545-556.

34. Halabi S, Collins EG, Thorevska N, Tobin MJ, Laghi F. Relationship between depressive symptoms and hypogonadism in men with COPD. COPD. 2011;8(5):346-353.

35. Akbaş T, Deyneli O, Sönmez FT, Akalın S. The pituitary-gonadal-thyroid and lactotroph axes in critically ill patients. Endokrynol Pol. 2016; 67(3):305-312.

36. Atlantis E, Fahey P, Cochrane B, Wittert G, Smith S. Endogenous testosterone level and testosterone supplementation therapy in chronic obstructive pulmonary disease (COPD): A systematic review and meta-analysis. BMJ Open. 2013;3(8):e003127. 